\title{
The Experimental Research of the Impact of Volleyball on the Physical and Mental Health for Female University Students Based on SPSS and Test Technology
}

\author{
Xueru $\mathrm{Wu}$ \\ Institute of Physical Education, Qiongzhou University, Wuzhishan, China \\ wu_xueru@126.com
}

Keywords:female university students; volleyball; physical and mental health

\begin{abstract}
The document-data method, questionnaire survey method, measurement method and analysis method are used in this article to study the female university students' cognition to playing volleyball, the volleyball playing situation of the female university students and the impact of this sport on the physical and mental health of them. The study result shows that over $90 \%$ female university students believe that playing volleyball can improve their physical and mental health. By using paired-sample t test and comparing the physical and mental indexes before and after playing basketball, we find that it can improve the respiratory function, enhance physical fitness and improve the psychological situation significantly.
\end{abstract}

\section{Introduction}

In recent years with the enrollment increase in the universities, the number of the students has been increasing. But because of the global economic crisis, the employment problem of the students is becoming more serious and the female university students have more burden than the male ones. The pressure of the employment problem and study influence the body and mind of the female students. So how to ease their bodies and minds is one problem to be solved.

The scientific research and practice show that attending the physical exercises can improve the body and psychological situation, which means that both the body and mind can be healthy. Volleyball is a team sport. Because of the low technical requirement, weak confrontation and popular attendance, volleyball is welcome among female university students. It also becomes one main teaching project in college sport courses. To study the impact of playing volleyball on the female students' mental and physical health is of great realistic significance.

\section{Object and Method of Research}

A. Research Object

We Use stratified sampling method grade female students from my school to select 96 students from the female students in our university. Firstly, we stratify according to the ages. Based on the proportion of the female students in each grade, we select 30,30, 20, 16 students in the four grades respectively as the training samples.

B. Training Method

Considering the courses arrangements, from 4 pm to 5:30 pm each Wednesday, Friday and Saturday, Saturday is the time to playing volleyball. At first, the teacher will teach some basic movements of playing volleyball and then the students can play in groups freely in the rest of the time. To guarantee the attendance, the result of it is recorded in the final term comprehensive evaluation after the negotiation with university.

C. Research Method

1) Document-data Method

By searching the relative papers in the field of science of physical culture and sports, pedagogy, health science and psychology in CNKI and Wanfang Database, we determine the basic contents of the research after studying the literatures.

2) Questionnaire Survey Method 
After the consulting the teachers who are engaging in sports and student work and interviewing the students, we make Questionnaire of Volleyball Fitness Situation of Female University Students and then implement the pre-survey and testify the validity and reliability. The result shows that the questionnaire is of great validity and reliability, which fits for the request of the research.

\section{3) Measurement Method}

Professional teachers of my school physical measurement will measure the height, weight, chest, waist, hips, pulse, blood pressure, vital capacity and heart rate, etc. According to the measurement, we can calculate the spiro-index (spiro-index=vital capacity/weight), the weight index (weight index=weight/height2) and the proportion of waist and hips (proportion of waist and hips=measurement of waist/measurement of hips).

We use the psychological investigation SCL-90 self-assessment symptom questionnaire to check the psychological status before and after the assessment. In this questionnaire there are 90 items which is concluded into 9 subscales, including summarization, forced symptoms, sensitive interpersonal relationship, depression, anxiety, hostile, terrorist, paranoid and psychotic.

4) Data Processing Method

We use scientific statistic package SPSS17.0 to analyze the data statistically. The comparison of the data before and after the training is tested by paired-sample $\mathrm{T}$ test. The testing level is 0.05 . The operation of the software is as below. Firstly, we choose "Analyze"; secondly, we choose "PairedSamples T Test..." in "Compare Mean"; when we see Fig. 1, press the two variables x1 and x2; at last we press "OK” to get the analysis result.

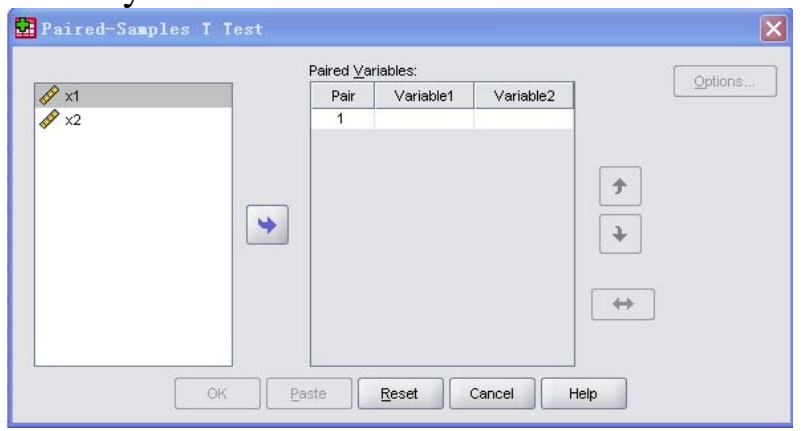

Figure 1. The dialog box of variable selection in Paired-Sample T Test

\section{Result and Analysis}

A.The Health Investigation Result of Female University Students Who Playing Volleyball 1)The Cognition of the University Students to the Value of Playing Volleyball

The result of the cognition of the university students to the value of playing volleyball is shown in Table 1 and Table 2. From Table 1 we can see the female students have overall positive recognition to the value of playing volleyball. $92.8 \%$ female students believe that playing volleyball can improve their physical and mental health. At the same time most of the students agree that it can enrich their spare time and can be benefit for the cultivation of the good habits. 94.3\% female university students regard it as a best relaxation. $81.5 \%$ believes that it will not influence their studies. The investigation of the aim of playing volleyball shows that $65.6 \%$ female students attending it is to strengthen their bodies, $17.7 \%$ for losing weight, $13.6 \%$ for relaxation and $3.1 \%$ for eliminating diseases.

TABLE I. THE COGNITION OF THE FEMALE UNIVERSITY STUDENTS TO THE VALUE OF PLAYING VOLLEYBALL

\begin{tabular}{|l|l|l|l|l|l|}
\hline \multicolumn{1}{|c|}{ Invested items } & $\begin{array}{c}\text { Totally } \\
\text { agree }\end{array}$ & Agree & Disagree & Totally disagree & Not known \\
\hline $\begin{array}{l}\text { Playing volleyball can improve mental and physical } \\
\text { health. }\end{array}$ & 67.5 & 25.3 & 5.2 & 2.0 & 0 \\
\hline Playing volleyball can enrich the spare time. & 63.7 & 20.9 & 11.4 & 2.7 & 1.3 \\
\hline Playing volleyball can develop good habits. & 47.9 & 43.8 & 3.8 & 1.4 & 3.1 \\
\hline Playing volleyball is a good way of relaxation. & 52.6 & 41.7 & 3.9 & 1.8 & 0 \\
\hline Playing volleyball frequently can affect the study. & 3.5 & 9.4 & 39.8 & 41.7 & 5.6 \\
\hline
\end{tabular}

TABLE II. 
TABLE III. THE FEMALE UNIVERSITY STUDENTS’ AIM OF PLAYING VOLLEYBALL

\begin{tabular}{|c|l|l|l|l|}
\hline & Strengthening the body & Eliminating the illness & Relaxation & Losing weight \\
\hline Number of persons & 63 & 3 & 13 & 17 \\
\hline Proportion (\%) & 65.6 & 3.1 & 13.6 & 17.7 \\
\hline
\end{tabular}

\section{2)The Situation of the Female University Students Playing Volleyball}

The frequency and time of the female university students playing volleyball are shown in Table 3. From this table, most of them play volleyball less than twice a week; each time most of them play volleyball over half an hour; they can not assure the exact time to play volleyball, which means that it is not popular among the female students. Universities and colleges should guide the female students to play volleyball more often.

TABLE IV. THE FREQUENCY AND TIME OF THE FEMALE UNIVERSITY STUDENTS PLAYING VOLLEYBALL

\begin{tabular}{|c|l|l|l|}
\hline \multicolumn{1}{|c|}{ Items } & \multicolumn{1}{|c|}{ Frequency } & Number of Persons & Proportion (\%) \\
\hline \multirow{4}{*}{ Times of playing volleyball } & Everyday & 5 & 5.2 \\
\cline { 2 - 4 } & 3 times/week & 28 & 29.2 \\
\cline { 2 - 4 } & $1-2 /$ week & 54 & 56.3 \\
\cline { 2 - 4 } & $1-3 /$ month & 9 & 9.3 \\
\hline \multirow{4}{*}{ Time of each exercise (minute) } & $<15$ & 4 & 4.2 \\
\cline { 2 - 4 } & $15-30$ & 29 & 30.2 \\
\cline { 2 - 4 } & $31-45$ & 43 & 44.8 \\
\cline { 2 - 4 } & $>45$ & 20 & 20.8 \\
\hline \multirow{5}{*}{ Week schedule of playing volleyball } & Fixed dates & 34 & 35.4 \\
\cline { 2 - 4 } & Holidays & 10 & 10.4 \\
\cline { 2 - 4 } & Fixed time of each day & 7 & 4.3 \\
\cline { 2 - 4 } & Uncertain & 45 & 46.9 \\
\hline
\end{tabular}

When playing volleyball, 81.3\% female university students tend to play with acquaintances; 3.1\% students usually play with the strangers; $15.6 \%$ has no fixed teammates. Volleyball is a kind of team sports. When playing, the members should coordinate with others, so most of the female university students prefer to play with acquaintances. The result is shown in Table 4.

TABLE V. THE VOLLEYBALL PARTNERS OF THE FEMALE UNIVERSITY STUDENTS

\begin{tabular}{|c|l|l|}
\hline Partners & Number of persons & Proportion \\
\hline Acquaintances & 78 & 81.3 \\
\hline Strangers & 3 & 3.1 \\
\hline Not fixed & 15 & 15.6 \\
\hline
\end{tabular}

The feelings of the female university students when playing volleyball are shown in Table 5 . From it, we can see $77 \%$ female students will sweat; $6.3 \%$ will feel a little hot; $2.1 \%$ has no special feelings. This shows that most of the female students can have the good effect of exercises when playing volleyball.

TABLE VI. THE BODY FEELINGS OF THE FEMALE UNIVERSITY STUDENTS WHEN PLAYING VOLLEYBALL

\begin{tabular}{|c|c|c|}
\hline Body feelings & Number of persons & Proportion \\
\hline Much sweat & 27 & 28.1 \\
\hline Some sweat & 47 & 48.9 \\
\hline Little sweat & 14 & 14.6 \\
\hline A little hot & 6 & 6.3 \\
\hline No special feelings & 2 & 2.1 \\
\hline
\end{tabular}

B.The Impact of Playing Volleyball on the Function of Lung and Heart of the Female University Students.

The result of the lung and heart functions after and before a workout is shown in Table 6. From it we can see that after 8 weeks exercises, the systolic pressure declines greatly after a workout, and the difference has statistic significance; while the vital capacity increases greatly. The index of the vital capacity and spiro-index are higher than that before the workout. But the indexes of pulse and diastolic pressure don't change greatly. This result shows that aerobic exercises at low and middle load of volleyball training can improve the inspiration function of the female university students. But it has little impact on cardiovascular system and physiological and skill levels. 
TABLE VII. THE FUNCTIONS OF HEART AND LUNG OF THE FEMALE UNIVERSITY STUDENTS BEFORE AND AFTER PLAYING VOLLEYBALL（ $\mathrm{N}=96$ )

\begin{tabular}{|c|l|l|c|}
\hline \multicolumn{1}{|c|}{ Index } & Before a workout & After a workout & P \\
\hline Pulse (b/min) & $79.65 \pm 2.72$ & $75.48 \pm 2.36$ & $>0.05$ \\
\hline Diastolic Pressure (kpa) & $72.59 \pm 2.47$ & $75.27 \pm 2.29$ & $>0.05$ \\
\hline Systolic Pressure (kpa) & $112.55 \pm 3.14$ & $106.31 \pm 2.93$ & $<0.05$ \\
\hline Vital Capacity (ml) & $2951.12 \pm 118.54$ & $3118.39 \pm 106.28$ & $<0.05$ \\
\hline Spiro-index (ml/kg) & $57.62 \pm 2.31$ & $65.87 \pm 2.53$ & $<0.05$ \\
\hline
\end{tabular}

C.The Impact of Playing Volleyball on the Figures of the Female University Students

The measurement of the figures of the female university students before and after playing volleyball is shown in Table 7 . In this table, the weight of the students declines greatly after playing volleyball. So do the waist, the indexes of weight and the proportion of measurement of the waist and the hips. The difference has the statistical significance. But the changes of the measurements of height, chest, arms and hips are not remarkable. This shows that playing volleyball can effectively improve the health of the female university students.

TABLE VIII. THE FIGURE CHANGES OF THE FEMALE UNIVERSITY STUDENTS BEFORE AND AFTER PLAYING VOLLEYBALL（ $\mathrm{N}=96$ )

\begin{tabular}{|c|l|l|c|}
\hline Index & Before a workout & After a workout & P \\
\hline Height $(\mathbf{c m})$ & $161.75 \pm 3.24$ & $161.91 \pm 3.20$ & $>0.05$ \\
\hline Weight $\mathbf{( k g})$ & $56.21 \pm 4.83$ & $57.53 \pm 3.55$ & $<0.05$ \\
\hline Measurement of chest (cm) & $83.17 \pm 1.08$ & $83.59 \pm 1.07$ & $>0.05$ \\
\hline Measurement of arms (cm) & $22.96 \pm 0.72$ & $22.64 \pm 0.71$ & $>0.05$ \\
\hline Measurement of waist (cm) & $68.41 \pm 2.57$ & $65.18 \pm 2.33$ & $<0.05$ \\
\hline Measurement of hips (cm) & $92.48 \pm 1.79$ & $92.63 \pm 1.80$ & $>0.05$ \\
\hline Index of weight $(\mathbf{k g} / \mathbf{m}$ ) & $21.48 \pm 2.15$ & $20.04 \pm 1.98$ & $<0.05$ \\
\hline Proportion of measurement of waist and hips & $73.97 \pm 1.14$ & $70.37 \pm 1.09$ & $<0.05$ \\
\hline
\end{tabular}

D. The Impact of Volleyball on the Psychological Status of Female University Students

Using psychological syndrome table SCL-90 to evaluate the psychological status of female university students, we can get the results of the psychological syndrome before and after playing volleyball, which is shown in Table 8 and Fig. 2. From Table 8, we can find that the psychological status has been greatly improved after playing volleyball for 8 weeks. The syndrome of summarization, forced symptoms, sensitive interpersonal relationship, depression, anxiety, hostile, terrorist, paranoid and psychotic can be improved. Only the change of the summarization symptoms before and after the workout has no statistical significance, which shows that volleyball can improve the psychological status of female university students.

TABLE IX. THE COMPARISON OF SCL-90 ASSESSMENT RESULTS BEFORE AND AFTER PLAYING VOLLEYBALL $(\mathrm{N}=96)$

\begin{tabular}{|c|l|l|c|}
\hline Syndrome & Before a workout & After a workout & P \\
\hline Summarization & $1.524 \pm 0.395$ & $1.496 \pm 0.328$ & $>0.05$ \\
\hline Forced symptoms & $1.723 \pm 0.432$ & $1.557 \pm 0.401$ & $<0.05$ \\
\hline Sensitive interpersonal relationship & $1.705 \pm 0.357$ & $1.436 \pm 0.318$ & $<0.05$ \\
& & & \\
\hline Depression & $1.582 \pm 0.336$ & $1.368 \pm 0.295$ & $<0.05$ \\
\hline Anxiety & $1.407 \pm 0.269$ & $1.273 \pm 0.254$ & $<0.05$ \\
\hline Hostile & $1.280 \pm 0.283$ & $1.151 \pm 0.278$ & $<0.05$ \\
\hline Terrorist & $1.506 \pm 0.274$ & $1.311 \pm 0.270$ & $<0.05$ \\
\hline Paranoid & $1.203 \pm 0.255$ & $1.102 \pm 0.235$ & $<0.05$ \\
\hline Psychotic & $1.232 \pm 0.234$ & $1.121 \pm 0.227$ & $<0.05$ \\
\hline
\end{tabular}




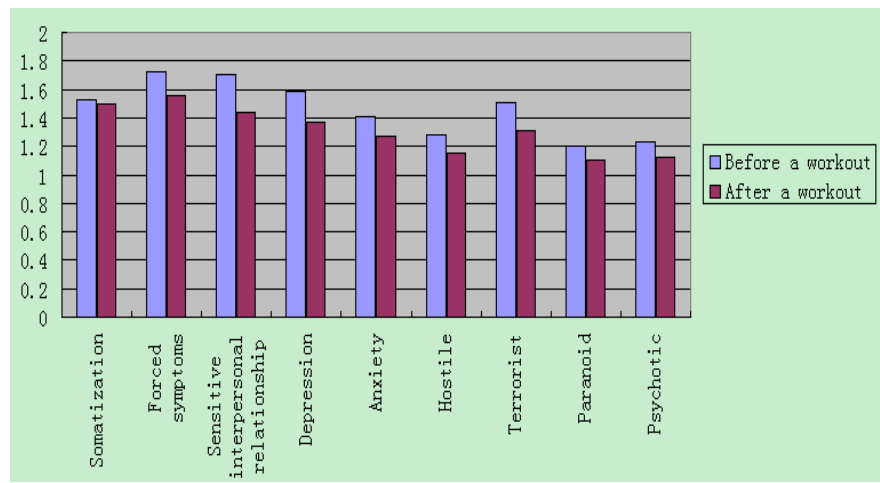

Figure 2. The comparison of the SCL-90 results before and after a workout of the female university students

\section{Conclusion}

The result of the research shows that most of the female university students have positive recognition towards the value of playing volleyball. But volleyball isn't very popular among the female students. The students can have an exercise when playing volleyball. After 8 weeks volleyball training, their respiratory systems and health can be greatly improved. And their negative psychological situation can be significantly eased. In all words, playing volleyball can improve the physical and mental health effectively. We can improve the mental and physical healthy growth of the female university students by developing volleyball in the colleges and universities.

\section{References}

[1] Wang Yanrong, The Experimental Research of Impact of Different Sports on the Psychological Health of College Students, Suzhou University Master’s Thesis, 2007

[2] Cao Yang, The Application of Exercise Prescription Teaching Mode in College Soft Volleyball Selective Course Teaching [J], Qiqihar Medical College Journal, 2010(4)

[3] Tian Hongwei, The Impact of Volleyball on Female Student of our University [J], Education Innovation Guide, 2012(7) : 208

[4] Liu Decheng, The Positive Effect of Soft Volleyball on the Psychological Health of Female University Students [J], Ganshu Radio and TV University Journal, 2008,18(1) : 80-81.

[5] Li Zhengxian, The Positive Effect of Volleyball on the Mental and Physical Health of Students

[J], Teaching in Forest Area, 2011(8):127-128

[6] Xue Hong, Chen Zhu, and Zhang Hong, Science of Physical Culture and Sports of School [M], Beijing, Beijing Normal University Press, 2009

[7] Liu Meijuan, The Experimental Research of the Teaching Effect of Soft and Hard Volleyball on the University Female Students in Normal PE, Shandong Normal University Master's Thesis, 2009

[8] Li Jinling, The Relation between Volleyball and Physical and Mental Health of Students [J], Scientific and Technological Information (Academic Edition), 2008(24): 561-562.

[9] Le Yuzhong, The Factors Influencing General Undergraduate Volleyball Teaching [J], Guangzhou Institute of Physical Education Journal, 2009(2) 